\title{
BMJ
}

\section{Physical interventions to interrupt or reduce the spread of respiratory viruses: systematic review}

\author{
Tom Jefferson, researcher, ${ }^{1}$ Chris Del Mar, dean, ${ }^{2}$ Liz Dooley, managing editor, Cochrane Acute Respiratory \\ Infections Group, ${ }^{2}$ Eliana Ferroni, researcher, ${ }^{1}$ Lubna A Al-Ansary, Shaikh Abdullah S Bahamdan research \\ chair, ${ }^{4}$ Ghada A Bawazeer, researcher, ${ }^{5}$ Mieke L van Driel, professor of general practice, ${ }^{2,3}$ Ruth Foxlee, \\ information specialist, ${ }^{6}$ Alessandro Rivetti, information specialist ${ }^{7}$
} ${ }^{1}$ Acute Respiratory Infections
Group, Cochrane Collaboration,
Rome, Italy
${ }^{2}$ Faculty of Health Sciences and
Medicine, Bond University, Gold
Coast, Australia

${ }^{3}$ Department of General Practice and Primary Health Care, Ghent University, Belgium

${ }^{4}$ Department of Family and Community Medicine, College of Medicine, King Saud University,

Riyadh, Saudi Arabia

${ }^{5}$ Department of Clinical Pharmacy and King Khalid University Hospital, King Saud University,

Riyadh, Saudi Arabia

${ }^{6}$ Department of Health Sciences, University of York, York

${ }^{7}$ Cochrane Vaccines Field, Azienda Sanitaria Locale, Alessandria, Italy Correspondence to: T Jefferson, Cochrane Acute Respiratory Infections Group, 00061 Anguillara

Sabazia, Rome, Italy

jefferson.tom@gmail.com

Cite this as: BMJ 2009;339:b3675 doi:10.1136/bmj.b3675

\section{ABSTRACT}

Objective To review systematically the evidence of effectiveness of physical interventions to interrupt or reduce the spread of respiratory viruses.

Data sources Cochrane Library, Medline, OldMedline, Embase, and CINAHL, without restrictions on language or publication.

Data selection Studies of any intervention to prevent the transmission of respiratory viruses (isolation, quarantine, social distancing, barriers, personal protection, and hygiene). A search of study designs included randomised trials, cohort, case-control, crossover, before and after, and time series studies. After scanning of the titles, abstracts and full text articles as a first filter, a standardised form was used to assess the eligibility of the remainder. Risk of bias of randomised studies was assessed for generation of the allocation sequence, allocation concealment, blinding, and follow-up. Nonrandomised studies were assessed for the presence of potential confounders and classified as being at low, medium, or high risk of bias.

Data synthesis 58 papers of 59 studies were included. The quality of the studies was poor for all four randomised controlled trials and most cluster randomised controlled trials; the observational studies were of mixed quality. Meta-analysis of six case-control studies suggested that physical measures are highly effective in preventing the spread of severe acute respiratory syndrome:

handwashing more than 10 times daily (odds ratio 0.45 , $95 \%$ confidence interval 0.36 to 0.57 ; number needed to treat $=4,95 \%$ confidence interval 3.65 to 5.52 ), wearing masks (0.32, 0.25 to 0.40 ; NNT=6, 4.54 to 8.03$)$, wearing N95 masks (0.09, 0.03 to $0.30 ; \mathrm{NNT}=3,2.37$ to 4.06), wearing gloves $(0.43,0.29$ to 0.65 ; NNT $=5,4.15$ to 15.41), wearing gowns $(0.23,0.14$ to 0.37 ; NNT $=5,3.37$ to 7.12 ), and handwashing, masks, gloves, and gowns combined $(0.09,0.02$ to 0.35 ; NNT=3, 2.66 to 4.97$)$. The combination was also effective in interrupting the spread of influenza within households. The highest quality cluster randomised trials suggested that spread of respiratory viruses can be prevented by hygienic measures in younger children and within households. Evidence that the more uncomfortable and expensive N95 masks were superior to simple surgical masks was limited, but they caused skin irritation. The incremental effect of adding virucidals or antiseptics to normal handwashing to reduce respiratory disease remains uncertain. Global measures, such as screening at entry ports, were not properly evaluated. Evidence was limited for social distancing being effective, especially if related to risk of exposure-that is, the higher the risk the longer the distancing period.

Conclusion Routine long term implementation of some of the measures to interrupt or reduce the spread of respiratory viruses might be difficult. However, many simple and low cost interventions reduce the transmission of epidemic respiratory viruses. More resources should be invested into studying which physical interventions are the most effective, flexible, and cost effective means of minimising the impact of acute respiratory tract infections.

\section{INTRODUCTION}

Epidemic and pandemic new viral infections pose a serious threat worldwide. Several have occurred recently, including the current $\mathrm{H} 1 \mathrm{~N} 1$ pandemic influenza ${ }^{1}$ and the coronavirus outbreak that caused severe acute respiratory syndrome (SARS). ${ }^{2}$

Even non-epidemic acute respiratory tract infections place a serious burden on health and healthcare systems. Overall, epidemics account for most of the 7\% of total deaths from respiratory tract infections in the world. ${ }^{3}$ Our 2007 Cochrane review showed that physical interventions (personal hygiene, barriers, and distancing) are highly effective. ${ }^{4}$ However, the current mainstay of pandemic interventions still seems to be vaccines and antiviral drugs, with no evidence supporting their widespread use, ${ }^{5-10}$ especially against a seemingly mild threat such as the novel H1N1 virus. For example, in the most recent guidance document on planning for pandemic influenza from the World Health Organization, handwashing and masks were mentioned only twice and gloves and gowns once each, but vaccines and antivirals were cited 24 and 18 times, respectively. ${ }^{11}$ 
We carried out a systematic review to update our 2007 Cochrane review on the evidence of the effectiveness of public health measures such as isolation, distancing, and barriers to interrupt or reduce the spread of respiratory viruses.

\section{METHODS}

We considered trials (individual level or cluster randomised, or quasi-randomised), observational studies (cohort and case-control designs), and any other comparative design, carried out in people of all ages and provided that some attempt had been made to control for confounding. We included any intervention to prevent the transmission of respiratory viruses from animal to human or from human to human (isolation, quarantine, social distancing, barriers, personal protection, or hygiene) compared with no intervention ("do nothing") or another intervention. We excluded vaccines and antivirals.

Outcome measures were mortality, numbers of cases of viral illness, the severity of viral illness, or proxies for any of these, and other measures of disease burden (such as admissions to hospital).

\section{Search strategy}

We searched the Cochrane Central Register of Controlled Trials (Cochrane Library 2009, issue 2), Medline (1966 to May week 12009), OldMedline (1950 to 1965), Embase (1990 to Week 18, 2009), and CINAHL (1982 to May week 12009 ); see the web extra on bmj.com for the search terms used for Medline and the Cochrane Register of Controlled Trials (modified for OldMedline, Embase, and CINAHL). No language restrictions were applied. Filters for study design included trials, cohort, case-control and crossover studies, before and after, and time series. We scanned the references of included studies for other potentially relevant studies. When necessary we corresponded with the first authors of studies to elicit further information.

We scanned the titles and abstracts of the studies identified by our search. When a study seemed to meet our eligibility criteria or information was insufficient to exclude it, we obtained the full text articles. We used a standardised form to assess the eligibility of each study, on the basis of the full article.

\section{Quality assessment}

We analysed randomised and non-randomised studies separately. Risk of bias in the randomised studies was assessed for the method of randomisation, generation of the allocation sequence, allocation concealment, blinding, and follow-up. Non-randomised studies were assessed for the presence of potential confounders using the appropriate Newcastle-Ottawa scales ${ }^{12}$ for case-control and cohort studies, and a three point checklist for controlled before and after and ecological studies. $^{13}$

We assigned categories for risk of bias on the basis of the number of items judged inadequate in each study: up to one inadequate item represented a low risk of bias, up to three items a medium risk, and more than three items a high risk.

\section{Data extraction}

Two authors (TOJ, CDM) independently applied the inclusion criteria to all identified and retrieved articles. Three authors (EF, LA, GB) extracted data from the included studies and checked their accuracy on standard forms used by the Cochrane Vaccines Field, supervised and arbitrated by TOJ and CDM.

Aggregation of data depended on the study design, types of comparisons, sensitivity, and homogeneity of definitions of exposure, populations, and outcomes used. We calculated the $\mathrm{I}^{2}$ statistic for each pooled estimate to assess the impact of statistical heterogeneity. ${ }^{1415}$

When possible we carried out a quantitative analysis and summarised effectiveness as an odds ratio, with $95 \%$ confidence intervals. When a result was significant we calculated absolute intervention effectiveness as a percentage using the formula: intervention effectiveness $=1$-odds ratio. In studies that could not be pooled we used effect measures as reported by the authors-for example, risk ratios or incidence rate ratios, with 95\% confidence intervals or, when not available, $\mathrm{P}$ values.

\section{RESULTS}

Of a total 2958 potentially relevant studies scanned for the 2007 review and its 2009 update, 2790 were excluded on the basis of their titles or abstracts, and the full papers of the remaining 168 trials were retrieved. Fifty eight papers of 59 studies were finally included (table 1); eight of these studies were incorporated in the 2009 update. A list of excluded studies will be available in the published Cochrane update.

The quality of the included randomised controlled trials varied (see web extra table). Three of the four trials were poorly reported, with two papers (three studies) giving no description of the randomisation sequence, allocation, or allocation concealment. ${ }^{1617}$ One trial reported the generation of randomisation, but blinding was impossible owing to the nature of the intervention (gargling with water with or without povidone-iodine compared with standard gargling with no attempt to mask the taste of iodine).${ }^{18}$ Information provided in a subsequent brief report contradicted the original report. ${ }^{19}$ The design of the two trials was artificial and therefore the results were not generalisable to daily practice. ${ }^{17}$

The quality of the cluster randomised trials varied (see web extra table). Only the highest quality trials ${ }^{20-2229}$ reported cluster coefficients and carried out analysis of data by unit of (cluster) randomisation. Other common problems were a lack of description of randomisation procedures, partial reporting of outcomes, unclear numerators or denominators, unexplained attrition, ${ }^{23-26}$ and complete failure of double blinding ${ }^{27}$ or inappropriate choice of placebo. ${ }^{28}$ Two cluster randomised trials involving the use of face masks ${ }^{2930}$ by contacts of patients with influenza and influenza-like illness had poor compliance. This 
Table 1| Overview of results of physical interventions and types of evidence to interrupt or reduce the spread of respiratory viruses

\begin{tabular}{|c|c|c|c|c|c|c|}
\hline \multirow[b]{2}{*}{ Intervention } & \multicolumn{6}{|c|}{ Study design } \\
\hline & $\begin{array}{l}\text { Randomised } \\
\text { controlled trial }(n=4)\end{array}$ & $\begin{array}{l}\text { Cluster randomised } \\
\text { controlled trial }(n=14)\end{array}$ & $\begin{array}{l}\text { Case-control } \\
\qquad(n=7)\end{array}$ & $\begin{array}{l}\text { Prospective cohort } \\
\qquad(n=16)\end{array}$ & $\begin{array}{l}\text { Retrospective cohort } \\
\qquad(n=5)\end{array}$ & $\begin{array}{l}\text { Before and after } \\
\qquad(n=13)\end{array}$ \\
\hline Handwashing & - & $\begin{array}{l}\text { Three trials in children } \\
\text { showed effectiveness }\end{array}$ & $\begin{array}{l}\text { Six studies, odds ratio } \\
0.45(95 \% \text { confidence } \\
\text { interval } 0.36 \text { to } 0.57)\end{array}$ & $\begin{array}{l}\text { Two studies showed } \\
\text { effect on acute } \\
\text { respiratory tract infection } \\
\text { and two studies no effect }\end{array}$ & - & $\begin{array}{l}\text { One study in military } \\
\text { recruits: handwashing } \\
\text { more than five times daily } \\
\text { was effective }\end{array}$ \\
\hline $\begin{array}{l}\text { Handwashing with } \\
\text { antiseptic }\end{array}$ & - & $\begin{array}{l}\text { Three trials in children: in } \\
\text { two trials antiseptic more } \\
\text { effective; soap used as } \\
\text { antiseptic in one trial }\end{array}$ & - & $\begin{array}{l}\text { Two studies added effect } \\
\text { of antiseptic: no } \\
\text { difference in one study }\end{array}$ & - & - \\
\hline $\begin{array}{l}\text { Handwashing and surface } \\
\text { disinfection }\end{array}$ & - & $\begin{array}{l}\text { Four trials in children and } \\
\text { families: two studies } \\
\text { showed effectiveness }\end{array}$ & - & - & - & $\begin{array}{l}\text { One study in school was } \\
\text { effective }\end{array}$ \\
\hline Hand disinfection & $\begin{array}{l}\text { Three trials showed } \\
\text { effectiveness }\end{array}$ & - & - & - & - & - \\
\hline $\begin{array}{l}\text { Gargling with povidone- } \\
\text { iodine }\end{array}$ & $\begin{array}{l}\text { One trial showed } \\
\text { effectiveness }\end{array}$ & - & - & - & - & - \\
\hline $\begin{array}{l}\text { Virucidal impregnated } \\
\text { tissues }\end{array}$ & - & $\begin{array}{l}\text { One trial showed small } \\
\text { effect; two trials were } \\
\text { non-significant }\end{array}$ & - & $\begin{array}{l}\text { One study showed } \\
\text { effectiveness }\end{array}$ & - & - \\
\hline $\begin{array}{l}\text { Disinfection of living } \\
\text { quarters }\end{array}$ & - & - & $\begin{array}{l}\text { One study, odds ratio } \\
0.30(95 \% \text { confidence } \\
\text { interval } 0.23 \text { to } 0.39)\end{array}$ & - & - & - \\
\hline \multicolumn{7}{|l|}{ Barriers: } \\
\hline $\begin{array}{l}\text { Mask, gloves, gown } \\
\text { combined }\end{array}$ & - & - & $\begin{array}{l}\text { Two studies, odds ratio } \\
0.09 \text { ( } 95 \% \text { confidence } \\
\text { interval } 0.02 \text { to } 0.35)\end{array}$ & $\begin{array}{l}\text { One study: mask plus } \\
\text { gown showed no added } \\
\text { effect with handwashing }\end{array}$ & - & $\begin{array}{l}\text { Three studies combined } \\
\text { with isolation showed } \\
\text { effectiveness; mask and } \\
\text { gown added to isolation } \\
\text { was not effective in one } \\
\text { study; gown and gloves } \\
\text { were effective in } \\
\text { paediatric ward in one } \\
\text { study }\end{array}$ \\
\hline Mask & - & $\begin{array}{l}\text { One trial showed effect } \\
\text { only when mask was } \\
\text { combined with } \\
\text { handwashing « } 36 \text { hours } \\
\text { after onset of symptoms; } \\
\text { one trial showed no effect } \\
\text { of P2 mask }\end{array}$ & $\begin{array}{l}\text { Five studies, odds ratio } \\
0.32(95 \% \text { confidence } \\
\text { interval } 0.25 \text { to } 0.40)\end{array}$ & $\begin{array}{l}\text { Three studies: masks } \\
\text { effective (with air filter } \\
\text { safer) }\end{array}$ & $\begin{array}{l}\text { One study: harm related } \\
\text { to mask wearing }\end{array}$ & $\begin{array}{l}\text { One study in children's } \\
\text { hospital was effective }\end{array}$ \\
\hline N95 mask & - & - & $\begin{array}{l}\text { Two studies, odds ratio } \\
0.09 \text { ( } 95 \% \text { confidence } \\
\text { interval } 0.03 \text { to } 0.30)\end{array}$ & - & $\begin{array}{l}\text { One study: harm related } \\
\text { to wearing N95 mask }\end{array}$ & - \\
\hline Gloves & - & - & $\begin{array}{l}\text { Four studies, odds ratio } \\
0.43(95 \% \text { confidence } \\
\text { interval } 0.29 \text { to } 0.65)\end{array}$ & - & $\begin{array}{l}\text { One study: harm related } \\
\text { to wearing gloves }\end{array}$ & - \\
\hline Gown & - & - & $\begin{array}{l}\text { Four studies, odds ratio } \\
0.23(95 \% \text { confidence } \\
\text { interval } 0.14 \text { to } 0.37 \text { ) }\end{array}$ & - & $\begin{array}{l}\text { One study: harm related } \\
\text { to wearing gown }\end{array}$ & $\begin{array}{l}\text { One study: no added } \\
\text { effect in neonatal } \\
\text { intensive care unit }\end{array}$ \\
\hline Distancing & - & - & - & $\begin{array}{l}\text { One study showed no } \\
\text { effect in military recruits; } \\
\text { cohorting in hospital was } \\
\text { effective in two studies }\end{array}$ & $\begin{array}{l}\text { One study: cohorting in } \\
\text { paediatric wards was } \\
\text { effective; cohorting } \\
\text { alongwith handwashing } \\
\text { and gowns was effective } \\
\text { in one study in military } \\
\text { hospital }\end{array}$ & $\begin{array}{l}\text { Six studies: early } \\
\text { identification of cases and } \\
\text { isolation were effective }\end{array}$ \\
\hline Quarantine & - & - & - & $\begin{array}{l}\text { One study: isolation of } \\
\text { close contacts was } \\
\text { effective }\end{array}$ & $\begin{array}{l}\text { One study: isolation of } \\
\text { close contacts was } \\
\text { effective }\end{array}$ & - \\
\hline
\end{tabular}

illustrates the difficulty of using bulky equipment in clinical trials in the absence of a real threat. In one trial the intervention targeted (randomised) clusters comprising households of index patients with influenza, up to three days after the onset of symptoms in the index case. ${ }^{29}$ This almost certainly underestimates the effect of the interventions, given that influenza infectivity is highest soon after infection. Another study was underpowered to detect differences in effect between different types of masks. ${ }^{30} \mathrm{~A}$ further cluster randomised trial was rated as being at low risk of bias owing to careful evaluation of compliance in the intervention arm (hand sanitiser wipes and disinfection of surfaces). ${ }^{31}$ 
Five of the seven case-control studies had a medium risk of bias ${ }^{32-36}$ and two a low risk, ${ }^{3738}$ mostly because of inconsistencies in the text and lack of adequate description of controls (see web extra table). Six of the 16 prospective cohort studies had a low risk of bias, ${ }^{39-44}$ six a medium risk, ${ }^{45-50}$ and three a high risk (see web extra table). ${ }^{51-53}$ One was a brief report of a small study with insufficient details to allow assessment. ${ }^{54}$ All five retrospective cohort studies had a high risk of bias (see web extra table). ${ }^{55-59}$ Six of the 13 controlled before and after studies had a low risk of bias, ${ }^{60-65}$ two a medium risk, ${ }^{6677}$ and five a high risk (see web extra table). ${ }^{68-72}$ Many of the observational studies were poorly reported and the retrospective designs were prone to recall bias. The most common problem in all of these studies, however, was that circulation of the virus within the reference population was not reported, questioning the interpretation and generalisability of the conclusions.

Reported results from randomised studies

Handwashing with or without antiseptics

Three randomised controlled trials tested the effects of cleaning hands on inactivating the virus and preventing experimental colds due to rhinovirus. This resulted either in a reduction in the incidence of rhinovirus infection among volunteers using different combinations of acids for cleaning $(\mathrm{P}=0.025)^{17}$ or did not reach statistical significance $13 \% v 30 \%$ with combined denominator of only 60$).{ }^{17}$ When iodine treatment of the fingers was used, one of 10 volunteers in the intervention arm became infected compared with six of 10 in the placebo $\operatorname{arm}(\mathrm{P}=0.06$, Fisher's exact test $) .{ }^{16}$

Eight cluster randomised studies tested educational programmes to promote handwashing with or without antiseptic agents on the incidence of acute respiratory tract infections either in schools or in households. As a result of different definitions, comparisons, lack of reporting of cluster coefficients, and, in two cases, missing data for participants, ${ }^{2324}$ meta-analysis was not feasible. Three of the trials reported a lack of effect for the prevention of acute respiratory illness: risk ratios 0.94 (95\% confidence interval 0.66 to 2.43$)$ ) ${ }^{24} 0.97$ (0.72 to $1.30),{ }^{22}$ and 1.10 (0.97 to 1.24$) .{ }^{31}$ A possible explanation for the lack of effect is that because exposure to respiratory viruses is ubiquitous, repeated hand hygiene would be needed, which is not practical in busy settings such as schools. Nevertheless, the highest quality trials reported a significant decrease in respiratory illness in children aged up to 24 months (risk ratio $0.90,0.83$ to 0.97 ), although the decrease was not significant in older children $(0.95,0.89$ to 1.01$),{ }^{21}$ and a $50 \%(-65 \%$ to $-34 \%)$ lower incidence of pneumonia in children aged less than 5 years in a low income country. ${ }^{20}$ Another study reported a decrease in respiratory tract infections of up to $38 \%$ with additional hand rubbing with benzalkonium chloride (risk ratios 0.69 for incidence of absence due to illness and 0.71 for duration of absence). ${ }^{26}$ One study reported a $43 \%$ reduction in absenteeism from school with the use of alcohol gel in addition to handwashing. ${ }^{25}$ Repeated handwashing significantly reduced the incidence of colds by as much as $20 \%$ in two trials. ${ }^{2373}$

\section{Impregnated disposable handkerchiefs}

Three cluster randomised studies tested the effects of disposable handkerchiefs impregnated with virucide on the incidence and spread of acute respiratory tract infections. One study reported a reduced incidence from $14 \%$ to $5 \%$ in households over 26 weeks. ${ }^{27} \mathrm{~A}$ similar study reported a small non-significant (5\%) decrease across families. ${ }^{27}$ However, as the reduction in incidence was confined to primary illness, which would be unaffected by use of the tissues, it might be assumed that the tissues were ineffective. A community trial also reported a non-significant reduction in secondary attack rates of acute respiratory tract infection $(18.7 \% v 11.8 \%)$ during high circulation of influenza H3N2 and rhinoviruses in the community. ${ }^{28}$ This result is likely to be an underestimate because of the barrier effect of the untreated tissue wipes used as control.

\section{Gargling}

One trial from Japan tested the effects of gargling with water compared with gargling with povidone-iodine or gargling as usual. ${ }^{18}$ This trial is linked by its registration number to a subsequent short report ${ }^{19}$ and the reporting of the two is confusing. The authors suggest that gargling with water is effective against mild forms of acute respiratory tract infection but not the more severe forms. The incidence rate ratio for gargling with water was 0.64 (95\% confidence interval 0.41 to 0.99 ) and for gargling with povidone-iodine was 0.89 (0.60 to 1.33). The authors also found that gargling with water may attenuate the symptoms of the disease. Gargling with povidone-iodine seemed to affect compliance because two participants switched to using water. Perhaps this potentially important study, totalling 387 participants in three arms, should be repeated in a larger population and with clearer reporting.

\section{Face masks}

Two cluster randomised trials assessed the effects on transmission of wearing face masks. In one study carried out in Hong Kong ${ }^{29}$ face masks were worn after a rapid diagnosis for influenza. Households of the index case were randomised to wearing face masks plus education, handwashing with alcohol sanitiser soap plus education, or education on illness prevention (control group). Surgical face masks were worn by all household members when the index patient was at home. The authors concluded that if face masks plus hand hygiene were implemented within 36 hours of the onset of symptoms in the index patient, then the transmission of influenza was significantly decreased (adjusted odds ratio 0.33 , 95\% confidence interval 0.13 to 0.87$)$. This is likely to be an underestimate of the effect because of the study design.

An Australian trial carried out over two winters assessed the effect of surgical masks, P2 masks, or no masks on the prevention of influenza-like illness and influenza in households. ${ }^{30}$ Although the intention to 
treat analysis showed no effect, sensitivity analysis showed that adherence to use of $\mathrm{P} 2$ or surgical masks significantly reduced the risk of influenza-like illness (hazard ratio $0.26,95 \%$ confidence interval 0.09 to 0.77). Under the assumption that the incubation period is equal to one day (the most probable value for the two most common viruses isolated, influenza $n=21$ and rhinovirus $n=26$ ), adherence to the use of $P 2$ or surgical masks significantly reduced the risk of influenza-like illness, with a hazard ratio of 0.26 ( 0.09 to $0.77 ; \mathrm{P}=0.015$ ) However, compliance with respirator use in a family setting is expected to be poor unless there is a clear impending risk.

\section{Reported results from case-control studies}

Six of the seven case-control studies assessed the impact of public health measures to curb the spread of severe acute respiratory syndrome during February to June 2003 in China, Singapore, and Vietnam. Homogeneity of case definition, agent, settings, and outcomes allowed meta-analysis (table 2, figure). Binary data were pooled; as none of the comparisons showed significant heterogeneity, a fixed effects model was used. Although continuous data were often available, the variables were different and measured in different units, with standard deviations usually missing, which made meta-analysis impossible. Studies reported that disinfection of living quarters was highly effective in preventing the spread of severe acute respiratory syndrome (odds ratio $0.30,95 \%$ confidence interval 0.23 to 0.39$)^{32}$; handwashing for a minimum of 11 times daily prevented most cases $(0.45,0.36$ to 0.57 ; all six studies $),{ }^{32-353738}$ wearing simple masks was highly effective $(0.32,0.25$ to 0.40 ; five studies), ${ }^{32-3538}$ wearing N95 masks was even more effective $(0.09,0.03 \text { to } 0.30 \text {; two studies })^{3337}$, wearing gloves was effective $(0.43,0.29$ to 0.65 ; three studies), ${ }^{333537}$ wearing gowns was also effective $(0.23$, 0.14 to 0.37 ; four studies), ${ }^{33353738}$ and all approaches combined achieved high effectiveness $(0.09,0.02$ to 0.35; two studies). ${ }^{33}$ All studies selected cases from hospitals, except one ${ }^{32}$ which chose cases of probable severe acute respiratory syndrome reported to the Department of Health in Hong Kong. A seventh case-control study ${ }^{36}$ assessed the impact of environmental, administrative, and host factors in 86 wards in 21 hospitals in Guangzhou and 38 wards in five hospitals in Hong Kong during the severe acute respiratory syndrome pandemic. Six significant risk factors were identified: minimum distance between beds of 1 m or less (odds ratio $6.94,1.68$ to 28.75 ), availability of washing or changing facilities for staff $(0.12,0.02$ to 0.97 ), whether resuscitation was ever done on the ward $(3.81,1.04$ to 13.87$)$, whether staff worked while they had symptoms (10.55, 2.28 to 48.87$)$, whether any index patient or the first patient with severe acute respiratory syndrome admitted to a ward required oxygen therapy $(4.30,1.00$ to 18.43$)$, and whether any index patients required bilevel positive airway pressure ventilation $(11.82,1.97$ to 70.80$)$.

\section{Prospective cohort studies}

Handwashing with or without antiseptics

Using an alcohol rub in students' communal residences resulted in significantly fewer symptoms (reductions of 14.8\% to 39.9\%) and lower absenteeism (40\% reduction). ${ }^{47}$ In a much cited small experimental study, virucidal paper handkerchiefs containing citric acid interrupted the transmission of colds caused by rhinovirus and transmitted through playing cards: $42 \%$ of students allocated to reusable cotton handkerchiefs developed colds compared with none using the disposable virucidal tissues. ${ }^{40}$ Few studies reported interventions in the day care setting, either in staff or patients. Perhaps more than the addition of portable virucidal hand foam as an adjunct to handwashing, one educational programme on handwashing for staff of a day care centre for adults was effective in reducing rates of respiratory tract infection from 14.5-10.4 per 100 person months to $5.7(\mathrm{P}<0.001)$, with an accompanying decline in viral isolates. ${ }^{41}$ This confirmed an earlier report on the effectiveness of a handwashing programme in reducing absenteeism due to influenza-like illness in a primary school. ${ }^{46}$

Two studies with a high risk of bias reported on the effectiveness of education, a handwashing routine, and education of kindergarten children, parents, and staff in correct sneezing and coughing procedures, although the incidence of infections in the control and test centres fluctuated considerably. ${ }^{51}$ The programme was not, however, effective in reducing absenteeism due to acute respiratory tract infections (risk ratio $0.79, \mathrm{P}=$ $0.756) .{ }^{52}$

A prospective cluster open label crossover cohort study assessed the effectiveness of a hand sanitiser in conjunction with handwashing at will using soap and water in a private elementary school in California. Use of the sanitiser was associated with a reduction in absenteeism due to illness by $41.9 \%$ (reduction in respiratory illnesses of $49.7 \%$ over the 10 weeks of the study). ${ }^{45}$ An education programme on infection control that reinforced handwashing and other hygiene measures in a nosocomial setting was associated with a reduction in the number of organisms present on hands and surfaces and of acute respiratory tract infections, whereas the tabulated data suggested the opposite (incidence rate 4.15 per 1000 patient days in the test homes $v 3.15$ in the control homes). ${ }^{50}$

\section{Goggles and masks with or without triage}

A study found that wearing a goggle and mask apparatus was effective in healthcare workers visiting and caring for children aged up to 5 years with respiratory syncytial virus and symptoms of respiratory tract disease (5\% illness rate in goggle wearers $v 61 \%$ in no goggle controls). ${ }^{39}$ Rapid laboratory diagnosis, cohort nursing, and wearing gowns and gloves for all contacts of children infected with respiratory syncytial virus significantly reduced the risk of nosocomial respiratory syncytial virus infection (odds ratio 0.013 to 0.76$){ }^{43}$ But another similar study reported no effect of adding both gowns and masks to the usual handwashing 
Table $2 \mid$ Pooled estimates of effect from case-control studies of public health interventions to interrupt the transmission of severe acute respiratory syndrome

$\begin{array}{lccc}\text { Intervention } & \begin{array}{c}\text { No of studies } \\ \text { (references) }\end{array} & \begin{array}{c}\text { Odds ratio } \\ (95 \% \mathrm{Cl})\end{array} & \begin{array}{c}\text { Intervention } \\ \text { effectiveness }\end{array} \text { (\%) }\end{array}$

*1 minus odds ratio.

routine on the development of illness in staff caring for infants with respiratory tract disease $(4 / 30$ in the handwashing group $v 5 / 28$ in the handwashing, gown, and mask group, $\mathrm{P}>0.20$ ) possibly due to the described poor compliance with the barrier protocol. ${ }^{47}$ Strict procedures of triage and infection control to stop transmission of severe acute respiratory syndrome from infected children to carers and visitors of a large hospital at the height of the epidemic in 2003 in Hong Kong was effective as no healthcare worker became ill, in contrast with experiences in other institutions. ${ }^{42} \mathrm{~A}$ small study comparing the N95 mask with paper surgical masks in volunteers found that surgical masks, even when worn in multiple layers (up to five), filtered ambient particles poorly. ${ }^{54}$ This principle was confirmed in another small study of air filtration to prevent the spread of droplets. ${ }^{44}$

\section{Distancing}

One study carried out during the severe acute respiratory syndrome pandemic in Taiwan assessed the effects of two types of quarantine: level A (after close exposure to people with severe acute respiratory syndrome) and level B (travellers who sat within three rows of someone infected with severe acute respiratory syndrome on a plane or were returning from WHO designated areas affected by severe acute respiratory syndrome). ${ }^{53}$ The odds ratio for developing severe acute respiratory syndrome with level A quarantine was 2.7 and with level B quarantine was 10.5. The probability of contracting severe acute respiratory syndrome differed in those aged less than 20 years $(0.09 \%$ for level A quarantine $v 0.02 \%$ for level B quarantine). The authors concluded that by placing only those with known exposure to someone with severe acute respiratory syndrome in quarantine the number of people quarantined could have been reduced. The characteristics (length and circumstances) of each type of quarantine were not, however, described.

One study ${ }^{49}$ took place in a US training facility for military recruits. It aimed to test whether contact with people entering the recruits' units affected the rate of influenza-like illness and to disentangle the role of environmental and person to person factors in transmission. The study compared the incidence of influenza-like illness in closed and open units depending on the ease of access by contagious (convalescent) people. The authors found no difference in incidence but extensive sampling of facilities that had been empty for a month showed persistence of adenovirus 4 (the main agent of influenza-like illness at the time in the community and the only agent tested for). This suggests a powerful influence of environmental factors in the pathogenesis of influenza-like illness, with a reduced role of person to person spread.

\section{Retrospective cohort studies \\ Distancing}

Two retrospective cohort studies investigated isolating children aged less than 3 years with suspected respiratory syncytial virus. Transmission was diminished by "up to $60 \%$ " in one study ${ }^{56}$ but not in the other. ${ }^{55}$ Isolation of cases during the 2003 severe acute respiratory syndrome epidemic in China was reported to limit transmission only to those who had contact at home or in hospital with a patient showing symptoms of severe acute respiratory syndrome (attack rates for carers $31 \%, 95 \%$ confidence interval $20 \%$ to $44 \%$; for visitors $9 \%, 3 \%$ to $22 \%$; for those living with someone with severe acute respiratory syndrome $5 \%, 3 \%$ to $9 \%$ ) but not to contacts living in the same building, working with cases, or having no contact with cases during the incubation period. This suggests that quarantine should be extended only for contacts of patients with symptoms of severe acute respiratory syndrome. ${ }^{57}$ Another brief report carried out in 2003 during the epidemic in a military hospital in Taiwan and 86 control hospitals, compared an integrated infection control policy to protect against infection with normal isolation procedures; only two healthcare workers from the military hospital became infected with severe acute respiratory syndrome compared with 43 suspected and 50 probable cases in the control hospitals. $^{58}$

\section{Harms of personal protective equipment}

A study of healthcare workers assessed possible harms caused by the use of personal protective equipment during the severe acute respiratory syndrome pandemic. ${ }^{59}$ Survey results showed that acne, itch, and rash were the most common harms reported after wearing a N95 mask $(60 \%, 51 \%$, and 36\%) and that dry skin, itch, and rash were reported by glove users $(73 \%, 56 \%$, and 38\%). Other harms were reported by small numbers of users. This study, although retrospective, is important as it points to reasons for poor compliance with barrier interventions.

\section{DISCUSSION}

Physical interventions are highly effective against the spread of a broad range of respiratory viruses.

Before drawing generalisations from the studies in our systematic review, however, we need to consider several features. The settings of the studies, carried out over four decades, were heterogeneous, ranging from suburban schools ${ }^{23455170}$ to military barracks, ${ }^{4964}$ intensive care units, and paediatric wards ${ }^{6168}$ in high 
income countries; slums in low income countries ${ }^{20}$ family units in China ${ }^{29}$; travellers in Taiwan ${ }^{53}$; and day care centres for children with special needs with a high teacher to pupil ratio. ${ }^{71}$ Few attempts were made to obtain socioeconomic diversity-for example, by involving more schools in the evaluations of the same programme. ${ }^{45}$ We were able to identify few studies from low income countries, where the highest burden lies and where cheap interventions are so critical. Even in high income countries, such as Israel, the dramatic reduction in acute respiratory tract infections subsequent to school closure may have been related to the country's large child population (34\%). Limited availability of over the counter drugs and national universal comprehensive health insurance with consequent doctor prescribed symptomatic treatment may further limit the generalisability of the findings. ${ }^{70}$

\begin{tabular}{|c|c|c|c|c|c|c|}
\hline \multirow{2}{*}{$\begin{array}{l}\text { Study or } \\
\text { subcategory }\end{array}$} & \multicolumn{2}{|c|}{$\begin{array}{c}\text { No with infection/ } \\
\text { No in group }\end{array}$} & \multirow{2}{*}{\multicolumn{2}{|c|}{$\begin{array}{c}\text { Odds ratio } \\
\text { (fixed) }(95 \% \mathrm{Cl})\end{array}$}} & \multirow{2}{*}{$\begin{array}{l}\text { Weight } \\
\text { (\%) }\end{array}$} & \multirow{2}{*}{$\begin{array}{c}\text { Odds ratio } \\
\text { (fixed) }(95 \% \mathrm{Cl})\end{array}$} \\
\hline & Cases & Control & & & & \\
\hline \multicolumn{7}{|c|}{ Frequent handwashing } \\
\hline Lau $2004^{32}$ & $61 / 330$ & $222 / 660$ & $\rightarrow$ & & 57.26 & $0.45(0.32$ to 0.62$)$ \\
\hline Nishiura $2005^{37}$ & $15 / 25$ & $56 / 90$ & - & & 4.62 & $0.91(0.37$ to 2.25$)$ \\
\hline Seto $2003^{33}$ & $10 / 13$ & $227 / 241$ & - & & 2.55 & $0.21(0.05$ to 0.83$)$ \\
\hline Teleman $2004^{38}$ & $27 / 36$ & $46 / 50$ & 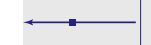 & & 4.57 & 0.26 (0.07 to 0.93$)$ \\
\hline Wu $2004^{34}$ & $73 / 94$ & $253 / 281$ & $\longrightarrow$ & & 13.45 & $0.38(0.21$ to 0.72$)$ \\
\hline Yin $2004^{35}$ & $28 / 77$ & $97 / 180$ & $\longrightarrow$ & & 17.56 & $0.49(0.28$ to 0.85$)$ \\
\hline Total $(95 \% \mathrm{Cl})$ & 575 & 1502 & - & & 100.00 & 0.45 (0.36 to 0.57$)$ \\
\hline \multicolumn{7}{|c|}{ Test for heterogeneity: $\chi^{2}=4.58, \mathrm{df}=5, \mathrm{P}=0.47, \mathrm{I}^{2}=0 \%$} \\
\hline \multicolumn{7}{|c|}{ Test for overall effect: $z=6.56, P<0.001$} \\
\hline \multicolumn{7}{|l|}{ Wearing mask } \\
\hline Lau $2004^{32}$ & $93 / 330$ & $388 / 660$ & $=$ & & 71.85 & $0.28(0.21$ to 0.37$)$ \\
\hline Nishiura $2005^{37}$ & $8 / 25$ & $35 / 90$ & - & & 4.00 & $0.74(0.29$ to 1.90$)$ \\
\hline Seto $2003^{33}$ & $0 / 13$ & $51 / 241$ & 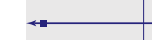 & & 2.10 & 0.14 (0.01 to 2.34$)$ \\
\hline Wu $2004^{34}$ & $25 / 94$ & $121 / 281$ & $\rightarrow$ & & 17.22 & $0.48(0.29$ to 0.80$)$ \\
\hline Yin $2004^{35}$ & $68 / 77$ & $178 / 180$ & - & & 4.82 & $0.08(0.02$ to 0.40$)$ \\
\hline Total $(95 \% \mathrm{Cl})$ & 539 & 1452 & 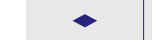 & & 100.00 & $0.32(0.25$ to 0.40$)$ \\
\hline \multicolumn{7}{|c|}{ Test for heterogeneity: $\chi^{2}=9.62, d f=4, P=0.05, I^{2}=58.4 \%$} \\
\hline \multicolumn{7}{|c|}{ Test for overall effect: $z=9.52, P<0.001$} \\
\hline \multicolumn{7}{|l|}{ Wearing gloves } \\
\hline Nishiura $2005^{37}$ & $8 / 25$ & $30 / 90$ & & & 12.18 & 0.94 (0.36 to 2.43$)$ \\
\hline Seto $2003^{33}$ & $4 / 13$ & $117 / 241$ &. & - & 11.39 & 0.47 (0.14 to 1.57$)$ \\
\hline Teleman $2004^{38}$ & $10 / 36$ & $22 / 50$ & $\rightarrow$ & & 18.27 & $0.49(0.20$ to 1.23$)$ \\
\hline Yin $2004^{35}$ & $37 / 77$ & $136 / 180$ & $=-$ & & 58.15 & 0.30 (0.17 to 0.52$)$ \\
\hline Total $(95 \% \mathrm{Cl})$ & 151 & 561 & - & & 100.00 & $0.43(0.29$ to 0.65$)$ \\
\hline \multicolumn{7}{|c|}{ Test for heterogeneity: $\chi^{2}=4.33, \mathrm{df}=3, \mathrm{P}=0.23, \mathrm{I}^{2}=30.6 \%$} \\
\hline \multicolumn{7}{|c|}{ Test for overall effect: $z=4.07, P<0.001$} \\
\hline \multicolumn{7}{|l|}{ Wearing gown } \\
\hline Nishiura $2005^{37}$ & $2 / 25$ & $25 / 90$ & & & 12.82 & $0.23(0.05$ to 1.03$)$ \\
\hline Seto $2003^{33}$ & $0 / 13$ & $83 / 241$ & & & 11.29 & $0.07(0.00$ to 1.20$)$ \\
\hline Teleman $2004^{38}$ & $5 / 36$ & $13 / 50$ & . & & 12.02 & $0.46(0.15$ to 1.43$)$ \\
\hline Yin $2004^{35}$ & $27 / 77$ & $128 / 180$ & $\rightarrow-$ & & 63.87 & $0.22(0.12$ to 0.39$)$ \\
\hline Total $(95 \% \mathrm{Cl})$ & 151 & 561 & $<$ & & 100.00 & $0.23(0.14$ to 0.37$)$ \\
\hline \multicolumn{7}{|c|}{ Test for heterogeneity: $\chi^{2}=2.10, d f=3, P=0.55, I^{2}=0 \%$} \\
\hline \multirow{2}{*}{\multicolumn{3}{|c|}{ Test for overall effect: $z=5.99, P<0.001$}} & 0.10 .20 .51 & 25 & 10 & \\
\hline & & & $\begin{array}{l}\text { Favours } \\
\text { intervention }\end{array}$ & & & \\
\hline
\end{tabular}

Effect of frequent handwashing or wearing masks, gloves, or gowns on prevention of cases of severe acute respiratory syndrome
Limitations of the evidence

The quality of the methods varied in these studies but may reflect the difficult and real life circumstances in which they were carried out. Hasty design of interventions for public health crises, particularly the six case-control studies of severe acute respiratory syndrome, is understandable but less so when no randomisation (not even by cluster) was carried out in several unhurried cohort and before and after studies. Randomisation could often have involved minimal disruption to the delivery of services. Inadequate reporting made interpretation of before and after studies difficult. In the trials a considerable loss of information resulted from incomplete or no reporting of randomisation, ${ }^{17}$ blinding, ${ }^{27}$ numerators and denominators, ${ }^{2324}$ interventions, outcomes, ${ }^{48}$ participant attrition, ${ }^{50}$ confidence intervals, ${ }^{43}$ and cluster coefficients. ${ }^{23}$ Potential biases (such as cash incentives for participants ${ }^{48}$ ) were not discussed. Some authors seemed to confuse cohort designs with those of before and after designs, which elaborated conclusions unsupported by their data..$^{50}$

Methodological quality was sometimes eroded by the need to deliver behavioural interventions in the midst of service delivery. ${ }^{51}$ None the less, even when suboptimal designs were selected, trial authors rarely attempted to articulate potential confounders. A commonly ignored confounder specific to this area was the huge variability in incidence of viruses. ${ }^{5670}$ Sometimes this was tackled in the study design, ${ }^{41}$ even in controlled before and after studies (one study attempted to correlate admissions for respiratory syncytial virus with circulating respiratory syncytial virus in the community). ${ }^{66}$ One pilot study was carried out during a period of low viral circulation in the northern hemisphere (early summer), whereas the subsequent full study was carried out from January to September. ${ }^{29}$

Another study attempted to link exposure (measured as nasal excretions) and infection rate in the periods before and after intervention. ${ }^{61}$ Inappropriate placebos caused design problems. In some studies the placebo probably carried sufficient effect to dilute the intervention effects. ${ }^{28}$ Two attempts probably failed because placebo handkerchiefs were impregnated with a dummy compound that stung the users' nostrils. ${ }^{27}$ Some studies used impractical interventions. Volunteers subjected to the intervention hand cleaner (organic acids) were not allowed to use their hands between cleaning and virus challenge, so the effect of normal use of the hands on the intervention remains unknown. ${ }^{17}$ Although $2 \%$ aqueous iodine is a successful antiviral intervention when painted on the hands it causes cosmetic staining and is impractical for all but those at the highest risk of epidemic contagion. ${ }^{16} \mathrm{Com}-$ pliance with interventions, especially with educational programmes and N95 masks, was a problem in several studies. N95 masks also caused harm such as rash and acne, further limiting the compliance of healthcare workers. ${ }^{59}$ Routine long term implementation of some of the measures assessed in this review would be problematic, particularly maintaining strict hygiene and barrier routines for long periods. In the absence of 
a real threat of a serious epidemic, this would probably be feasible only in highly motivated environments, such as hospitals. Most of the study authors commented on the considerable logistic burden imposed by barrier routines at the community level.

\section{Clear benefits}

The highest quality cluster randomised trials indicate that most effect on preventing the spread of respiratory viruses can be expected from hygienic measures in younger children and household members of index cases. Perhaps this is because younger children are least capable of hygienic behaviour and have longer lived infections and greater social contact, thereby acting as portals of infection into the household. ${ }^{21}$ Additional benefit from reduced transmission from children to other members of the household is broadly supported by the results of other study designs where the potential for confounding is greater. The seven casecontrol studies suggest that implementing barriers to transmission, isolation, and hygienic measures are effective with the use of relatively cheap interventions to contain epidemics of respiratory viruses. We found limited evidence of the superior effectiveness of barrier devices to droplets such as the N95 masks over simple surgical masks. N95 masks are respirators with 95\% filtration capability against non-oily particulate aero sols. ${ }^{38}$ Although they are more expensive and uncomfortable (especially if worn for long periods) than simple surgical masks, they may be useful in high risk situations. We are aware of at least one randomised trial comparing different masks for influenza (NCT00756574).

\section{Uncertainties}

It is uncertain whether the incremental effect of adding virucidals or antiseptics to normal handwashing actually decreased the burden of respiratory tract disease outside the confines of the rather atypical studies reported on here. The extra benefit may have been, at least in part, accrued by confounding additional routines. Studies preventing transmission of respiratory syncytial virus and similar viruses seemed to be closer to real life and suggest good effectiveness of physical barriers. However, concerns about the methodological quality of the controlled before and after studies suggest that the benefits may have been caused by differences in the populations, especially in virus infection rates. These were poorly reported in most studies. The effectiveness of gargling with water compared with an antiseptic should be tested further in a larger trial with better masking of the possible addition of the antiseptic liquid.

The lack of proper evaluation of global and highly resource intensive measures such as screening at entry ports and social distancing was disappointing. The handful of studies (mostly done during the severe acute respiratory syndrome epidemic) does not allow any firm conclusions. Encouragingly, differential quarantine periods based on length and intensity of exposure may have minimised the transmission of severe acute respiratory syndrome. This observation should be tested further when possible.

We would like to emphasise the potential importance of one study, that in the US military training facility, which suggests that as yet unknown environmental factors may be powerful stimuli in the genesis of influenza-like illness and that person to person spread may be a limited form of transmission. ${ }^{49}$

\section{Policy and evidence}

The disparity in effectiveness between the high profile of influenza vaccines and antivirals and the low profile of physical interventions is striking. Public health recommendations are almost completely based on the use of vaccines and antivirals despite the lack of strong evidence. ${ }^{1}$ Vaccines work best in those who are universally considered least to need them ${ }^{10}$ namely, healthy adults. Antivirals may be harmful and their benefits depend on the identification of the agent (influenza). ${ }^{8}$ But physical interventions are effective, safe, flexible, universally applicable, and relatively cheap. There are many complex reasons for this disparity. Influenza vaccines, for instance, target only a limited proportion of influenza-like illnesses (around 10\% to 7\%). ${ }^{78}$ The comparative rarity of influenza as a cause of influenza-like illness affects the calculation of the effectiveness of influenza specific vaccines and antivirals. If the incidence of influenza in the unvaccinated population is low then the vaccine effectiveness ratio will be close to 1 and effectiveness low. However, physical interventions are directed against all viral diseases and therefore calculation of their effectiveness is sensitive only to the incidence of influenza-like illness, not of influenza. In addition, physical interventions are relatively cheap. The cost of masks ranges from $\$ 0.16(£ 0.09 ; € 0.11)$ to $\$ 1.9$ each depending on make and complexity, from soft surgical masks to N95 masks. ${ }^{74}$ Prices are higher for well known brands and different designs and materials, although bulk purchase would result in sizeable discounts.

Our review shows that public health measures can be highly effective, especially when they are part of a structured programme that includes instruction and education and when they are delivered together.

\section{Implementation of physical interventions}

One major problem with physical interventions is poor compliance, especially during periods of low threat as reported in many of the included studies. All the mentioned physical interventions require change in behaviour, which is the most important barrier to implementation. A need exists to further research, introduce, and evaluate such programmes aimed at changing behaviour. Extra resources should be made available for these. Further large scale pragmatic trials to evaluate the best combinations are clearly required. Funding for these studies remains a problem, however. Randomised controlled trials with a pragmatic design, similar to the trial by Luby et al, ${ }^{20}$ should be carried out whenever possible. Perhaps the impressive effect of hygienic measures aimed at younger children is 


\section{WHAT IS ALREADY KNOWN ON THIS TOPIC}

\section{Respiratory tract infection is the main cause of burden of disease worldwide}

The world is increasingly concerned about pandemics of viral origin

Interventions to minimise the spread of infection focus on influenza specific vaccines and stockpiling of antivirals

\section{WHAT THIS STUDY ADDS}

Hygiene and physical barriers, especially handwashing, wearing masks, and isolation of potentially infected patients, are effective in preventing the spread of viral infections

These interventions should be given higher priority in the preparation and evaluation of national pandemics

Cheap and non-invasive interventions have the potential to reduce mortality and morbidity from viral respiratory tract infections

based on their poor capability of being hygienic. Although physical interventions are cheap and effective, their cost effectiveness should be evaluated in prospective studies. The role of environmental factors in the genesis of acute respiratory tract infections should be investigated further.

\section{Conclusions}

Based on the findings of this review, we recommend that handwashing programmes should be implemented nationwide, their effectiveness monitored, and their cost effectiveness evaluated. In situations of high risk of transmission, barrier measures should be implemented such as wearing gloves, gowns, and masks with a filtration apparatus, and isolation of likely cases. Most effort should be concentrated on reducing transmission from young children through regular education at school on hygiene. In addition, society should invest in more comfortable and better designed face masks and barrier apparatus, which would increase compliance with their use.

We thank Anne Lyddiatt, Stephanie Kondos, Tom Sandora, Kathryn Glass, Max Bulsara, Rick Shoemaker, Allen Cheng, Bill Hewak, Adi Prabhala, and Sree Nair for their comments on or contributions to present and previous versions of the review; Jørgen Lous for translating a Danish paper and extracting data; Ryuki Kassai for translating a Japanese paper; Taixiang Wu for translating several Chinese papers; Luca De Fiore for supplying information on costs; and Michael Broderick for supplementary study information. LAA-A holds the Shaikh Abdullah S Bahamdan research chair for evidence based health care and knowledge translation at the College of Medicine, King Saud University, Riyadh, Saudi Arabia.

Contributors: TOJ, CDM, and LD drafted the protocol. LD, CDM, MVD, and TOJ edited the text of the previous version. RF and AR constructed and ran the search strategy. EF, LA and GAB extracted the data. TOJ, CDM, and MVD checked the data and wrote the final report. All authors contributed to the final report.

Funding: NHS research and development programme and National Health and Medical Research Council of Australia. The study sponsor had no role in study design, analysis, conclusions, drafting the report, or the decision to submit the report.

Competing interests: None declared

Ethical approval: Not required.

1 World Health Organization. Global alert and response: pandemic (H1N1) 2009. www.who.int/csr/disease/swineflu/en/, 2009.

2 Shute N. SARS hit home. US News World Rep 2003;134:38-42, 4.

3 World Health Organization. Health Statistics and health information systems: disease and injury regional estimates for 2004. www.who. int/healthinfo/global_burden_disease/estimates_regional/en/ index.html, 2009.

4 Jefferson T, Foxlee R, Del Mar C, Dooley E, Ferroni E, Hewak W, et al. Physical interventions to interrupt or reduce the spread of respiratory viruses: systematic review. BMJ 2008;336:77-80.

5 Jefferson T, Rivetti A, Harnden A, Di Pietrantonj C, Demicheli V. Vaccines for preventing influenza in healthy children. Cochrane Database Syst Rev

2008;(1):CD004879. DOI: 10.1002/14651858.CD004879.pub3.

6 Cates CJ, Jefferson T, Rowe B. Vaccines for preventing influenza in people with asthma. Cochrane Database Syst Rev 2008;(1):CD000364. http://highwire.stanford.edu/cgi/medline/ pmid;18425863.

7 Jefferson T, Di Pietrantonj C, Debalini MG, Rivetti A, Demicheli V. Study quality, concordance, take home message, funding and impact: their relationship in influenza vaccines studies. BMJ 2009;338:b354.

8 Jefferson T, Demicheli V, Rivetti D, Jones M, Di Pietrantonj C, Rivetti A. Antivirals for influenza in healthy adults: systematic review. Lancet 2006;367:303-13.

9 Jefferson T, Rivetti D, Rivetti A, Rudin M, Di Pietrantonj C, Demicheli V. Efficacy and effectiveness of influenza vaccines in elderly people: a systematic review. Lancet 2005;366:1165-74.

10 Jefferson T, Rivetti D, Di Pietrantonj C, Rivetti A, Demicheli V. Vaccines for preventing influenza in healthy adults. Cochrane Database of Systematic Reviews

2007;(2):CD001269. DOI: 10.1002/14651858.CD001269.pub3.

11 World Health Organization. Pandemic influenza preparedness and response: a WHO guidance document. Geneva: WHO, 2009.

12 Wells GA, Shea B, O'Connell D, Peterson J, Welch V, Losos M, et al. The Newcastle-Ottawa Scale (NOS) for assessing the quality of nonrandomised studies in meta-analyses. www.ohri.ca/programs/ clinical_epidemiology/oxford.htm, 2005.

13 Khan S.K, ter Riet G, Popay J, Nixon J, Kleijnen J. Stage II: conducting the review. Phase 5: study quality assessment. In: Khan S.K, ter Riet G, Glanville J, Sowden AJ, Kleijnen J, eds. Undertaking systematic reviews of research on effectiveness. CRD's guidance for carrying out or commissioning reviews. CRD report No 4. 2nd ed. York: University of York, 2000.

14 Higgins JP, Thompson SG. Quantifying heterogeneity in a metaanalysis. Stat Med 2002;21:1539-58.

15 Higgins JP, Thompson SG, Deeks JJ, Altman DG. Measuring inconsistency in meta-analyses. BMJ 2003;327:557-60.

16 Gwaltney JM Jr, Moskalski PB, Hendley JO. Interruption of experimental rhinovirus transmission. J Infect Dis 1980;142:811-5.

17 Turner RB, Biedermann KA, Morgan JM, Keswick B, Ertel KD, Barker MF. Efficacy of organic acids in hand cleansers for prevention of rhinovirus infections. Antimicrob Agents Chemother 2004; 48:2595-8.

18 Satomura K, Kitamura T, Kawamura T, Shimbo T, Watanabe M, Kamei M, et al. Prevention of upper respiratory tract infections by gargling: a randomized trial. Am J Prev Med 2005;29:302-7.

19 Kitamura T, Satomura K, Kawamura T, Yamada S, Takashima K, Suganuma N, et al. Can we prevent influenza-like illnesses by gargling? Intern Med 2007;46:1623-4.

20 Luby SP, Agboatwalla M, Feikin DR, Painter J, Billhimer W, Altaf A et al. Effect of handwashing on child health: a randomised controlled trial. Lancet 2005;366:225-33.

21 Roberts L, Smith W, Jorm L, Patel M, Douglas RM, McGilchrist C. Effect of infection control measures on the frequency of upper respiratory infection in child care: a randomised controlled study. Paediatrics 2000;105:738-42.

22 Sandora TJ, Taveras EM, Shih MC, Resnick EA, Lee GM Ross-Degnan D, et al. A randomized, controlled trial of a multifaceted intervention including alcohol-based hand sanitizer and handhygiene education to reduce illness transmission in the home. Paediatrics 2005;116:587-94.

23 Carabin H, Gyorkos TW, Soto JC, Joseph L, Payment P, Collet JP. Effectiveness of a training program in reducing infections in toddlers attending day care centers. Epidemiology 1999;10:219-27.

24 Kotch JB, Weigle KA, Weber DJ, Clifford RM, Harms TO, Loda FA, et al. Evaluation of an hygienic intervention in child day-care centers. Paediatrics 1994:94:991-4.

25 Morton JL, Schultz AA. Healthy hands: use of alcohol gel as an adjunct to handwashing in elementary school children. J Sch Nurs 2004:20:161-7.

26 White CG, Shinder FS, Shinder AL, Dyer DL. Reduction of illness absenteeism in elementary schools using an alcohol-free instant hand sanitizer. J Sch Nurs 2001;17:258-65.

27 Farr BM, Hendley JO, Kaiser DL, Gwaltney JM. Two randomised controlled trials of virucidal nasal tissues in the prevention of natural upper respiratory infections. Am J Epidemiol 1988;128:1162-72.

28 Longini IM Ir. Monto AS. Efficacy of virucidal nasal tissues in interrupting familial transmission of respiratory agents. A field trial in Tecumseh, Michigan. Am J Epidemiol 1988;128:639-44. 
29 Cowling BJ, Chan KH, Fang VJ, Cheng CKY, Fung ROP, Wai W, et al. Facemasks and hand hygiene to prevent influenza transmission in households: a randomized trial. Ann Intern Med 2009;151. www.annals.org/cgi/content/full/0000605-200910060$00142 \mathrm{v} 1$.

30 Maclntyre CR, Cauchemez S, Dwyer DE, Seale H, Cheung P, Browne G, et al. Face mask use and control of respiratory virus transmission in households. Emerg Infect Dis 2009;15:233-41.

31 Sandora TJ, Shih MC, Goldmann DA. Reducing absenteeism from gastrointestinal and respiratory illness in elementary school students: a randomized, controlled trial of an infection-control intervention. Pediatrics 2008;121(6):e1555-62.

32 Lau JT, Tsui H, Lau M, Yang X. SARS transmission, risk factors, and prevention in Hong Kong. Emerg Infect Dis 2004;10:587-92.

33 Seto WH, Tsang D, Yung RW, Ching TY, Ng TK, Ho M, et al. Effectiveness of precautions against droplets and contact in prevention of nosocomial transmission of severe acute respiratory syndrome (SARS). Lancet 2003;361:1519-20.

34 Wu J, Xu F, Zhou W, Feikin DR, Lin CY, He X. Risk factors for SARS among persons without known contact with SARS patients, Beijing, China. Emerg Infect Dis 2004;10:210-6.

35 Yin WW, Gao LD, Lin WS, Gao LD, Lin WS, Du L, et al. Effectiveness of personal protective measures in prevention of nosocomial transmission of severe acute respiratory syndrome. Chung-Hua Liu Hsing Ping Hsueh Tsa Chih 2004;25:18-22.

36 Yu IT, Xie ZH, Tsoi KK, Chiu YL, Lok SW, Tang XP, et al. Why did outbreaks of severe acute respiratory syndrome occur in some hospital wards but not in others? Clin Infect Dis 2007;44(8):1017-25.

37 Nishiura H, Kuratsuji T, Quy T, Phi NC, van Ban V, Ha LE, et al. Rapid awareness and transmission of severe acute respiratory syndrome in Hanoi French Hospital, Vietnam. Am J Trop Med Hyg 2005;73:17-25.

38 Teleman MD, Boudville IC, Heng BH, Zhu D, Leo YS. Factors associated with transmission of severe acute respiratory syndrome among health-care workers in Singapore. Epidemiol Infect 2004;135:797-803.

39 Agah R, Cherry JD, Garakian AJ, Chapin M. Respiratory syncytial virus (RSV) infection rate in personnel caring for children with RSV infections. Routine isolation procedure vs routine procedure supplemented by use of masks and goggles. Am J Dis Child 1987;141:695-7.

40 Dick EC, Hossain SU, Mink KA, Meschievitz CK, Schultz SB, Raynor WJ, et al. Interruption of transmission of rhinovirus colds among human volunteers using virucidal paper handkerchiefs. J Infect Dis 1986;153:352-6.

41 Falsey AR, Criddle MM, Kolassa JE, McCann RM, Brower CA, Hall WJ. Evaluation of a handwashing intervention to reduce respiratory illness rates in senior day-care centers. Infect Control Hosp Epidemiol 1999;20:200-2.

42 Leung TF, Ng PC, Cheng FW, Lyon DJ, So KW, Hon EK, et al. Infection control for SARS in a tertiary paediatric centre in Hong Kong. J Hosp Infect 2004;3:215-22.

43 Madge P, Paton JY, McColl JH, Mackie PL. Prospective controlled study of four infection-control procedures to prevent nosocomial infection with respiratory syncytial virus. Lancet 1992;340:1079-83.

44 Somogyi R, Vesely AE, Azami T, Preiss D, Fisher J, Correia J, et al. Dispersal of respiratory droplets with open vs closed oxygen delivery masks: implications for the transmission of severe acute respiratory syndrome. Chest 2004;125:1155-7.

45 Dyer DL, Shinder A, Shinder F. Alcohol-free instant hand sanitizer reduces elementary school illness absenteeism. Fam Med 2000;32:633-8.

46 Kimel LS. Handwashing education can decrease illness absenteeism. J Sch Nurs 1996;12:14-6, 8.

47 Murphy D, Todd JK, Chao RK, Orr I, McIntosh K. The use of gowns and masks to control respiratory illness in paediatric hospital personnel. Paediatr 1981;99:746-50.

48 White C, Kolble R, Carlson R, Lipson N, Dolan M, Ali Y, et al. The effect of hand hygiene on illness rate among students in university residence halls. Am J Infect Control 2003;31:364-70.

49 Broderick MP,Hansen C), Russell KL. Exploration of the effectiveness of social distancing on respiratory pathogen transmission implicates environmental contributions. J Infect Dis 2008;198(10):1420-6.

50 Makris AT, Morgan L, Gaber DJ, Richter A, Rubino IR. Effect of a comprehensive infection control program on the incidence of infections in long-term care facilities. Am J Infect Control 2000;28:3-7.

51 Niffenegger JP. Proper handwashing promotes wellness in child care. J Paediatr Health Care 1997;11:26-31.

52 Master D, Longe SH, Dickson H. Scheduled hand washing in an elementary school population. Fam Med 1997;29:336-9.
53 Wang TH, Wei KC, Hsiung CA, Maloney SA, Eidex RB, Posey DL, et al. Optimizing severe acute respiratory syndrome response strategies: lessons learned from quarantine. Am J Public Health 2007;97(suppl 1):S98-100.

54 Derrick JL, Gomersall CD. Protecting healthcare staff from severe acute respiratory syndrome: filtration capacity of multiple surgical masks. J Hosp Infect 2005;59:365-8.

55 Doherty JA, Brookfield DS, Gray J, McEwan RA. Cohorting of infants with respiratory syncytial virus. J Hosp Infect 1998;38:203-6.

56 Isaacs D, Dickson H, O'Callaghan C, Sheaves R, Winter A, Moxon ER. Handwashing and cohorting in prevention of hospital acquired infections with respiratory syncytial virus. Arch Dis Child 1991;66:227-31.

57 Ou JM, Dun Z, Li Q, Qin AL, Zeng G. Efficiency of the quarantine system during the epidemic of severe acute respiratory syndrome in Beijing, 2003. Chung-Hua Liu Hsing Ping Hsueh Tsa Chih 2003;24:1093-5.

58 Yen MY, Lin YE, Su IJ, Huang FY, Huang FY, Ho MS, et al. Using an integrated infection control strategy during outbreak control to minimize nosocomial infection of severe acute respiratory syndrome among healthcare workers. J Hosp Infect 2006;62:195-9.

59 Foo CC, Goon AT, Leow YH, Goh CL. Adverse skin reactions to personal protective equipment against severe acute respiratory syndrome-a descriptive study in Singapore. Contact Dermatitis 2006;55:291-4.

60 Hall CB, Douglas RG. Modes of transmission of respiratory syncytial virus. J Paediatr 1981;99:100-3.

61 Leclair JM, Freeman J, Sullivan BF, Crowley CM, Goldmann DA. Prevention of nosocomial respiratory syncytial virus infections through compliance with glove and gown isolation precautions. $N$ Engl J Med 1987;317:329-34.

62 Macartney KK, Gorelick MH, Manning ML, Hodinka RL, Bell LM. Nosocomial respiratory syncytial virus infections: the costeffectiveness and cost-benefit of infection control. Paediatrics 2000;106:520-6.

63 Pang X, Zhu Z, Xu F, Guo J, Gong X, Liu D, et al. Evaluation of contro measures implemented in the severe acute respiratory syndrome outbreak in Beijing, 2003. JAMA 2003;290:3215-2.

64 Ryan MA, Christian RS, Wohlrabe J. Handwashing and respiratory illness among young adults in military training. Am J Prev Med 2001;21:79-83.

65 Simon A, Khurana K, Wilkesmann A, Muller A, Engelhart S, Exner M, et al. Nosocomial respiratory syncytial virus infection: impact of prospective surveillance and targeted infection control. Int J Hyg Environ Health 2006;209:317-24.

66 Krasinski K, LaCouture R, Holzman RS, Waithe E, Bonk S, Hanna B. Screening for respiratory syncytial virus and assignment to a cohort at admission to reduce nosocomial transmission. J Paediatr 1990;116:894-8.

67 Pelke S, Ching D, Easa D, Melish ME. Gowning does not affect colonization or infection rates in a neonatal intensive care unit. Arch Paediatr Adolesc Med 1994;148:1016-20.

68 Gala CL, Hall CB, Schnabel KC, Pincus PH, Blossom P, Hildreth SW, et al. The use of eye-nose goggles to control nosocomial respiratory syncytial virus infection. JAMA 1986;256:2706-8.

69 Hall CB, Douglas RG Jr. Nosocomial respiratory syncytial viral infections. Should gowns and masks be used? Am J Dis Child 1981;135:512-5.

70 Heymann A, Chodick G, Reichman B, Kokia E, Laufer J. Influence of school closure on the incidence of viral respiratory diseases among children and on health care utilization. Paediatr Infect Dis J 2004;23:675-7.

71 Krilov LR, Barone SR, Mandel FS, Cusack TM, Gaber DJ, Rubino JR. Impact of an infection control program in a specialized preschool. Am J Infect Control 1996;24:167-73.

72 Snydman DR, Greer C, Meissner HC, McIntosh K. Prevention of nosocomial transmission of respiratory syncytial virus in a newborn nursery. Infect Control Hosp Epidemiol 1988;9:105-8.

73 Ladegaard MB, Stage V. Hand hygiene and sickness among small children attending day care centres. An interventional study. Ukesgrift von Laeger 1999;161:4396-400.

74 Amazon.com. Inovel 3100 series N95 respirator/surgical mask medium/large. www.amazon.com/dp/B002HRSO3Y/ ref $=$ asc df B002HRSO3Y879713? smid=A2I5DA0K14Z5W0\&tag=nextag-hpc-mp01-delta$20 \&$ linkCode $=$ asn $\&$ creative $=380341 \&$ creativeASIN $=$ B002HRSO3Y 2009

Accepted: 7 September 2009 